\title{
Respuesta inmunohumoral durante la nefrectomía abierta y laparoscópica de donante vivo. Modelo porcino experimental
}

\author{
Sáenz Medina J, Asuero de Lis MS*, Villafruela Sanz J**, Correa Gorospe C***, Cuevas B***, \\ Galindo Álvarez J****, Páez Borda A, Linares Quevedo AI, Marcén Letosa R**, Pascual Santos J**, \\ Burgos Revilla FJ*****
}

Servicio de Urología Hospital de Fuenlabrada. *Servicio de Anestesiología y Reanimación.

**Servicio de Nefrología. ${ }^{* * *}$ Unidad de Investigación. ${ }^{* * * * S e r v i c i o ~ d e ~ C i r u g i ́ a . ~}{ }^{* * * * *}$ Servicio de Urología. Hospital Ramón y Cajal. Universidad de Alcalá de Henares.

Actas Urol Esp. 2008;32(4):435-442

\section{RESUMEN}

RESPUESTA INMUNOHUMORAL DURANTE LA NEFRECTOMÍA ABIERTA Y LAPAROSCÓPICA DE DONANTE VIVO. MODELO PORCINO EXPERIMENTAL

Introducción: Se ha demostrado la menor agresividad quirúrgica provocada por el abordaje laparoscópico, en base a la medición de diversos marcadores de estrés postquirúrgico, entre los que se encuentran distintas interleuquinas (IL) y la proteína C reactiva (PCR). La endotelina 1 (ET-1) es un vasoconstrictor potente producido en el endotelio renal escasamente analizado en el curso de la cirugía laparoscópica. El objetivo del trabajo es analizar comparativamente la respuesta inmunohumoral inducida por las nefrectomías laparoscópica y abierta en un modelo experimental porcino, en base a la cuantificación de la PCR, las IL-2, 10, el factor de necrosis tumoral alfa (TNF alfa), y la ET-1.

Material y métodos: Se analizan comparativamente dos grupos de cerdos de 25-40 Kg, un grupo CONTROL (N=10) y grupo LAPAROSCÓPICO ( $\mathrm{N}=10)$, a los que se les realiza una nefrectomía abierta o laparoscópica respectivamente. Se determinó en sangre venosa periférica los niveles de PCR, IL-2, IL-10, TNF $\alpha$ y ET-1. Las determinaciones analíticas se realizaron en los momentos: basal, postcirugía, 1, 3, 5, y 7 días postquirúrgico.

Resultados: $\mathrm{El}$ análisis comparativo de ambos grupos demuestra un aumento estadísticamente significativo de la PCR $(1,44 \pm 0,88$ vs $1,32 \pm 0,14 \mathrm{mg} / \mathrm{dl}, \mathrm{p}=0,046), \mathrm{TNF} \alpha(131,14 \pm 41,37$ vs $57,19 \pm 23,71 \mathrm{pg} / \mathrm{ml}, \mathrm{p}>0,001)$ y ET-1 $(0,91 \pm 0,49$ vs $0,56 \pm 0,5 \mathrm{fmol} / \mathrm{ml}, \mathrm{p}=0,001$ ) del grupo abierto en comparación con el grupo control, así como una elevación de la IL2 en el grupo laparoscópico.

Conclusiones: La respuesta inmunohumoral inducida por la nefrectomía abierta es superior a la de la nefrectomía laparoscópica en el curso de la donación. La importancia de este hecho en el síndrome isquemia reperfusión o la función inmediata del injerto no está claramente establecida.

Palabras clave: Laparoscopia. Nefrectomía. Respuesta inmunohumoral.

\section{ABSTRACT \\ IMMUNE RESPONSE DURING LAPAROSCOPIC AND OPEN LIVING DONOR NEPHRECTOMY. AN EXPERIMENTAL PIG MODEL}

Introduction: It's been demonstrated laparoscopic access determines a lower surgical stress, by measurement of several markers as different interleuquines (IL) or C- reactive protein (CRP). Endothelin 1 (ET-1) is a powerful vasoconstrictor produced in renal endothelium scarcely studied in laparoscopy. The objective of this study is to analyze immune response during laparoscopic and open donor nephrectomy, in a porcine experimental model by means of measuring IL-2, 10, tumoral necrosis factor $\alpha(\mathrm{TNF} \alpha)$, CRP and ET-1.

Methods: Twenty pigs underwent left nephrectomy, 10 by laparoscopy and 10 by open approach in an experimental model. Both groups were monitorized IL-2, 10, TNF $\alpha$, ET-1 at basal, immediately post surgery, first, third, fifth and seventh days after procedure.

Results: The comparative analysis between groups demonstrated a significant increase in levels of CRP $(1,44 \pm 0,88$ vs $1,32 \pm 0,14 \mathrm{mg} / \mathrm{dl}, \mathrm{p}=0,046)$, TNF $\alpha(131,14 \pm 41,37$ vs $57,19 \pm 23,71 \mathrm{pg} / \mathrm{ml}, \mathrm{p}>0,001)$ and ET- $1(0,91 \pm 0,49$ vs 0,56 $\pm 0,5 \mathrm{fmol} / \mathrm{ml}, \mathrm{p}=0,001$ ) of open nephrectomy group, as a higher levels of IL-2 in laparoscopic group.

Conclusions: Open donor nephrectomy determines a higher immune response than laparoscopic approach. The importance of this fact over the ischemia-reperfusion syndrome or the immediate function of graft is not clearly established.

Keywords: Laparoscopy. Nephrectomy. Immune response. 
$P_{c}^{2}$ artiendo del estudio de la cascada de modificaciones fisiológicas producidas por la lesión tisular inducida por la cirugía, se han utilizado diversos marcadores para cuantificar el daño tisular y la respuesta inflamatoria del organismo local y sistémico a la cirugía. Entre los marcadores más utilizados destacan los reactantes de fase aguda, como la proteína $\mathrm{C}$ reactiva (PCR) o el fibrinógeno; las citocinas especialmente el factor de necrosis tumoral $\alpha$ (TNF $\alpha)$ y la interleucina 6 (IL-6), y los recuentos celulares de leucocitos, polimorfonucleares (PMN), linfocitos T o células "natural killer" (NK).

La cuantificación de estos marcadores ha permitido el estudio del impacto sobre el organismo de los diferentes abordajes quirúrgicos, demostrando que la laparoscopia provoca menor respuesta sistémica y proporciona un claro beneficio para el paciente, especialmente durante el postoperatorio inmediato ${ }^{1-13}$.

Una proteína reactante de fase aguda se define como aquella cuyas concentraciones plasmáticas aumentan o disminuyen al menos el 25\% durante los procesos inflamatorios. Estos cambios se deben, en su mayor parte, a variaciones en la síntesis proteica de los hepatocitos, inducidas por las citocinas proinflamatorias. Las acciones atribuidas a los reactantes de fase aguda incluyen la activación del sistema del complemento, la inhibición de proteinasas y la actividad antioxidante. Actualmente, los indicadores mas usados de fase aguda son la PCR, la velocidad de sedimentación globular (VSG) y el precursor del amiloide sérico A (SAA) ${ }^{8}$.

La PCR es el marcador más utilizado en cirugía porque presenta una mejor correlación con las variaciones en la actividad de los procesos inflamatorios y su espectro de cambio es mayor que el de la VSG. Se empieza a elevar a las 4-12 horas de la cirugía, alcanza su pico a las 24-72 horas y se mantiene elevada hasta las dos semanas. Existen numerosos trabajos que demuestran unos niveles menores de PCR tras laparoscopia que tras cirugía abierta ${ }^{14,15}$.

Las citocinas son mediadores solubles esenciales en la comunicación entre las células que participan en la regulación de la inflamación y de las respuestas inmunes. Son proteínas pequeñas de 8-80 Kd, producidas por una gran variedad de células que suelen actuar de forma autocrina (sobre la misma célula productora) o paracrina (sobre células cercanas). Su producción suele ser transitoria y se regula de forma estrecha, actuando a muy bajas con- centraciones. Actualmente se conocen más de 100 tipos de citocinas diferentes. Actúan como elementos integrantes de una red o sistema funcional con interconexiones en cascada. Además, son pleiotrópicas, es decir, actúan sobre varias células, en las que inducen múltiples efectos, a veces contradictorios y redundantes (solapamiento de unos efectos con otros) ${ }^{16}$.

Existen tres tipos de interleuquinas: proinflamatorias producidas por macrófagos, entre las que se encuentran la IL-1, IL-6, IL 8 y el TNF $\alpha$; proinflamatorias producidas por linfocitos $\mathrm{T}$ entre las que se encuentran la IL-2, interferón $\gamma$, y el TNF $\beta$, y supresoras de la respuesta inmune como la IL-10.

Numerosos trabajos en humanos y en animales han utilizado las citocinas para evaluar y cuantificar el daño tisular producido por la cirugía ${ }^{1-13}$. Se han realizado numerosos estudios que comparan la respuesta inflamatoria tras la cirugía laparoscópica o la cirugía abierta; si bien los resultados no son uniformes debido a la poca cantidad de estudios randomizados y la pequeña muestra estudiada. La mayoría de estudios encuentran una menor cantidad de IL circulantes tras abordaje laparoscópico que tras la cirugía abierta.

La ET-1 se ha descrito como un polipéptido con una fuerte acción vasoconstrictora. Se produce en el endotelio de las arterias arcuatas e interlobares, así como en las células del túbulo proximal ${ }^{17}$. Se han publicado algunos trabajos ${ }^{18,19}$ en los que se ha descrito el aumento de los niveles de esta molécula secundario al aumento de presión en la vena renal durante el neumoperitoneo. Este aumento de la ET1 se ha postulado como parcialmente responsable en los fenómenos de disminución del filtrado glomerular y de oliguria asociados a la laparoscopia ${ }^{18}$.

No existen referencias en la literatura ni a nivel clínico ni experimental que compare los niveles postquirúrgicos de ET-1 entre los abordajes laparoscópico y abierto. Sin embargo, se han llevado a cabo estudios en animales que analizan la evolución de los niveles de ET-1 tras el neumoperitoneo. Ambrose et al. ${ }^{19}$ realizaron un estudio en ratas en el que demostraron un aumento de de la expresión del gen de la ET-1, evaluado mediante inmunohistoquímica en las piezas de nefrectomía. Hamilton et al. ${ }^{18}$ objetivaron igualmente un aumento de los niveles de ET-1 tras la insuflación peritoneal de $\mathrm{CO}_{2}$. Sin embargo, este incremento no se puso de manifiesto en sangre arterial sistémica. 
El objetivo del estudio es evaluar la dimensión del estrés quirúrgico generado por las nefrectomía laparoscópica y abierta, respectivamente, en base a la cuantificación del daño tisular mediante marcadores de agresividad quirúrgica (PCR, IL-2, 10, TNF $\alpha$ y ET-1).

\section{MATERIAL Y MÉTODOS}

Basados en los datos obtenidos en otros estu$\operatorname{dios}^{20}$ de similares características a nuestro modelo experimental, tomando como variable indicadora la PCR, y de acuerdo con los objetivos establecidos previamente, se estableció en 20 el número de animales necesarios para rechazar la hipótesis nula (ausencia de diferencias en la PCR de ambos grupos a estudio), asumiendo una probabilidad del 5\% de identificar una diferencia en el PVR inexistente (error $\alpha$ ) y una probabilidad del 20\% de omitir (existiendo) una diferencia en la PCR entre ambos grupos (error beta). El poder estadístico del experimento es, por tanto, del $80 \%$.

Se obtuvieron dos grupos de 10 cerdos, un grupo ABIERTO ( $\mathrm{n}=10$ cerdos), utilizado como grupo control, en el que se realizó una nefrectomía por laparotomía media convencional; y un grupo LAPAROSCÓPICO: ( $\mathrm{n}=10$ cerdos), utilizado como grupo estudio en el que la nefrectomía se realizó vía laparoscópica.

\section{Técnica anestésica}

La inducción anestésica se realizó con $10 \mathrm{mg} / \mathrm{kg}$ de pentotal sódico y atropina $0,01 \mathrm{mg} / \mathrm{kg}$ por vía $\mathrm{IV}$. La ventilación se realizó con Fracción Inspirada de Oxígeno $\left(\mathrm{FiO}_{2}\right)$ de 1 , con un volumen corriente minuto (VM) inicial de $10 \mathrm{ml} / \mathrm{kg}$, ajustando este parámetro y la frecuencia respiratoria a la situación específica del momento del procedimiento quirúrgico, para intentar mantener valores de $\mathrm{CO}_{2}$ final espirado (ETCO2) alrededor de $45 \mathrm{~mm} \mathrm{Hg}$. El mantenimiento de la profundidad anestésica se llevó a cabo con Sevofluorano al 2-3\%, según requerimientos, junto con una perfusión continua de: $500 \mathrm{cc}$ de solución Ringer con $5 \mathrm{mg}$ de Remifentanilo, 0,15 mg de Fentanilo y $15 \mathrm{mg}$ de Vecuronio, a una velocidad de $140 \mathrm{ml} /$ hora. Se administraron dosis adicionales de relajante muscular según necesidad.

La hidratación del animal se realizó con la perfusión de la solución de Ringer previamente mencionada (140 ml/hora), además de una infusión continua de 500 cc de almidón (HES 130/0,4, Voluven $^{\mathrm{TM}} 6 \%$ ), durante la cirugía, a una velocidad de $100 \mathrm{ml} / \mathrm{h}$, lo que resulta una infusión de 8 $\mathrm{ml} / \mathrm{kg} /$ hora de líquidos IV, ajustando, además, bolos adicionales de $50 \mathrm{cc}$, de acuerdo con los parámetros hemodinámicas registrados y las pérdidas hemáticas.

Se monitorizaron las variables hemodinámicas y respiratorias.

Se determinó la profundidad anestésica mediante el registro de entropía, colocando los electrodos en idéntica situación al humano.

\section{Técnica quirúrgica}

Técnica quirúrgica de nefrectomía en el grupo ABIERTO $(N=10)$.

Tras la colocación en decúbito supino, se realizó una incisión de laparotomía media (Fig. 1), abriendo toda la pared abdominal y peritoneo, se procedió a la apertura del espacio laterocólico izquierdo, previa liberación de colon descendente, accediendo a retroperitoneo. Se disecaron y seccionaron la arteria y la vena renales izquierdas, accediendo posteriormente al uréter y procediéndose posteriormente a la liberación y extracción del riñón. El cierre por planos de pared abdominal se llevó a cabo con polyglactil y la piel con puntos sueltos de seda.

Técnica quirúrgica de nefrectomía en el grupo LAPAROSCÓPICO $(N=10)$.

Tras la colocación y preparación del animal en decúbito lateral derecho se realizó abordaje laparoscópico transperitoneal, previa colocación del trocar de Hasson mediante minilaparotomía de 1,5 cm

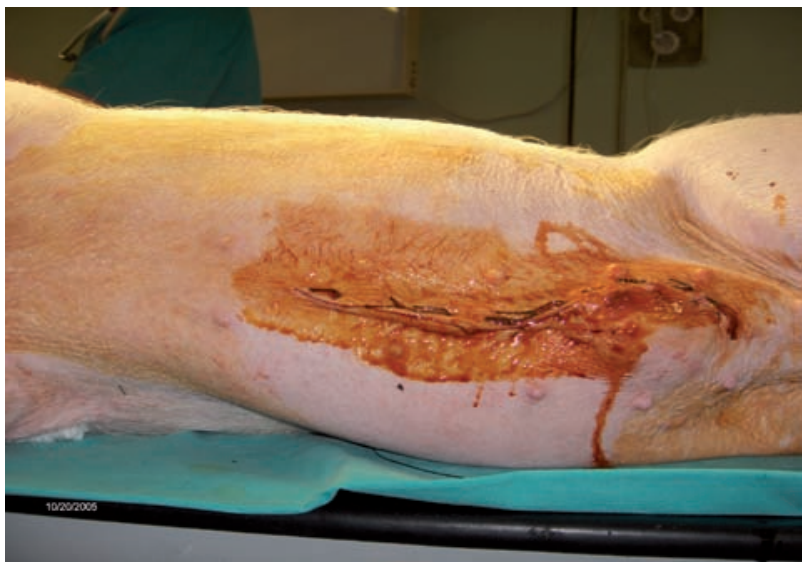

FIGURA 1. Imagen de laparotomía realizada en el grupo abierto. 
lateral a la línea mamaria, en el punto medio entre la duodécima costilla y la pala iliaca izquierdas. Se procedió a la insuflación hasta alcanzar una presión intrabdominal (PIA) de $12 \mathrm{~mm} \mathrm{Hg}$. El segundo trocar se colocó $4 \mathrm{~cm}$ lateral y caudal para manejar el instrumental con la mano derecha del cirujano y el tercer trocar de $5 \mathrm{~mm}, 4 \mathrm{~cm}$ lateral y craneal al trocar de Hasson (Fig. 2).

Se procedió a la apertura del espacio parietocólico izquierdo, accediendo a la celda renal y llevando a cabo la disección de la arteria renal izquierda. A continuación, se disecó el resto del pedículo vascular renal (Fig. 3) y el uréter, procediendo a su ligadura y sección, posteriormente se extrajo la pieza a través de minilaparotomía.

\section{Recogida de variables y procesamiento de muestras}

Se recogieron muestras en los dos grupos para la determinación de interleucinas (IL-2, IL-10 y TNF $\alpha$ ), PCR y ET-1, en los momentos basal, postcirugía, y

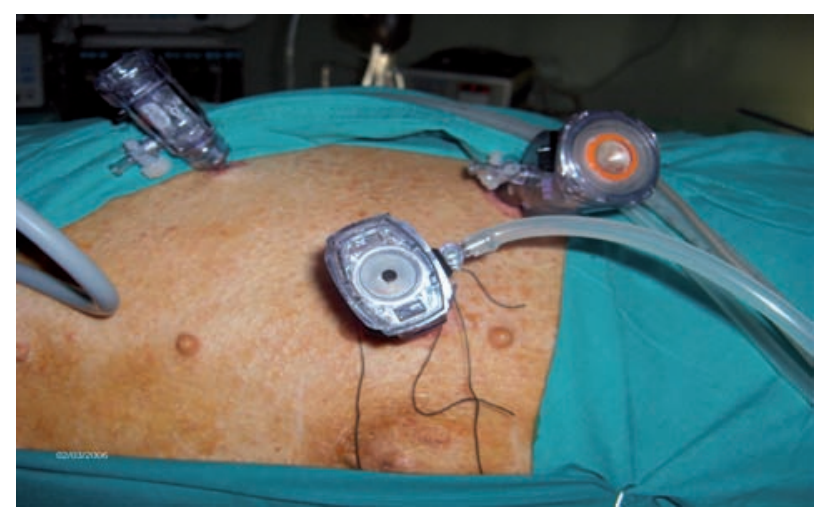

FIGURA 2. Imagen de colocación de los trócares para el acceso laparoscópico.

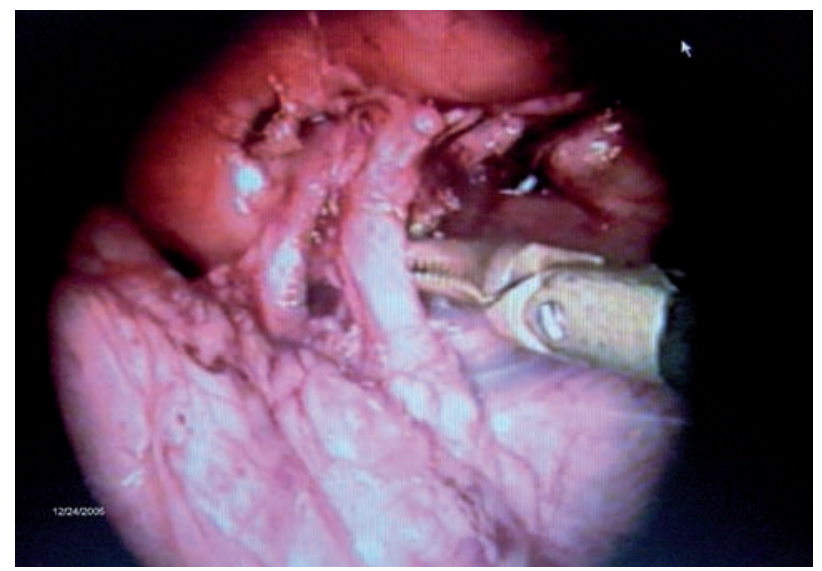

FIGURA 3. Imagen de disección de vasos renales en el grupo laparoscópico. al $1^{\mathrm{er}}, 3^{\mathrm{er}}, 5^{\mathrm{o}}$ y 7 días postoperatorios. Se extrajeron 10 cc de sangre venosa periférica (vena yugular derecha) que se depositaron en un tubo vacío (vacutainer), las muestras se centrifugaron, inmediatamente a $4^{\circ} \mathrm{C}$ durante 15 minutos a $3000 \mathrm{rpm}$. El plasma se depositó en alícuotas de $1 \mathrm{ml}$ en microtubos Eppendorf y se congeló a $-30^{\circ} \mathrm{C}$.

Las determinaciones de IL-2, IL-10 y TNF- $\alpha$ se realizaron mediante una técnica ELISA tipo sándwich (Quantikine. R \& D Systems. Wiesbaden, Germany) al igual que las de ET (1 -21) (Biomedica Medizinprodukte GMBH \& Co. Wien. Germany).

La cuantificación de PCR se efectuó mediante una técnica de aglutinación (Abbott Laboratorios. Wiesbaden. Germany).

\section{Método de análisis estadístico de los datos}

Como estimador de la tendencia central de las variables se utilizó la media, y como estimador de la dispersión se empleó la desviación estándar.

Previo a la comparación de las muestras, se procedió a la exploración de los datos, mediante el análisis de los diagramas de caja de las distribuciones y a la comprobación de la normalidad de las mismas con el test de Shapiro - Wilk, que comparan la distribución observada con una esperada en caso de seguir una ley normal.

Para comparar la diferencia entre las medias observadas, se utilizó el test de la t de Student, cuando se cumplieron las condiciones de normalidad explicadas previamente (diagramas de caja sin anomalías importantes y Shapiro - Wilk no significativo) y el supuesto de homocedasticidad (test de Levene no significativo). En caso contrario, se utilizó el test no paramétrico de la U de Mann - Whitney cuando no se cumplía el supuesto de normalidad, o se obtuvieron los valores corregidos del error estándar y los grados de libertad cuando no se cumplió el supuesto de homocedasticidad. Se utilizó el paquete informático SPSS v. 11.5.

\section{RESULTADOS}

La evolución de los valores la PCR, durante los primeros siete días postoperatorios, en los grupos abierto y laparoscópico, se muestra en la Figura 4.

De los resultados se desprende, por una parte la homogeneidad de los grupos, y por otra, el aumento progresivo de los niveles en sangre de PCR del grupo abierto, que sólo alcanza diferencias estadísticamente significativas, respecto al grupo laparoscópico, al $5^{\circ}$ día postoperatorio. Aunque en las otras tomas post- 


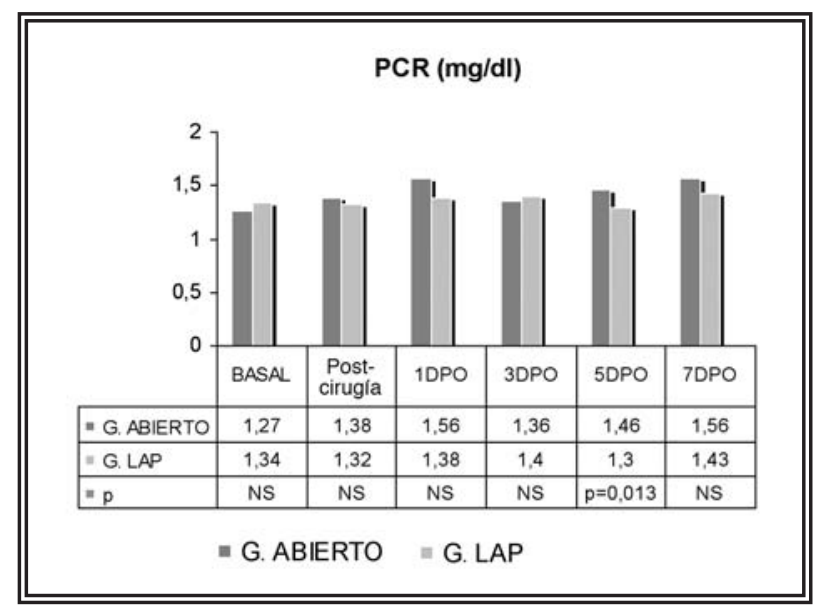

FIGURA 4. Evolución comparativa del valor PCR entre los grupos abierto y laparoscópico.

operatorias este parámetro presenta valores sólo ligeramente superiores, la diferencia de valor promedio de la PCR entre el grupo abierto $(1,44 \pm 0,88$ $\mathrm{mg} / \mathrm{dl})$ y el grupo laparoscópico $(1,32+0,14 \mathrm{mg} / \mathrm{dl})$ en el grupo laparoscópico, sí alcanza la significación estadística $(p=0,046)$. Por tanto, resulta que el nivel en sangre de PCR es mayor tras la nefrectomía abierta que tras la laparoscópica con una diferencia máxima al $5^{\circ}$ día postoperatorio.

Los valores en sangre de la IL 2, durante las primeras 24 horas postoperatorios en los grupos abierto y laparoscópico presentaron un comportamiento diferente, con tendencia al descenso en el grupo abierto, en contraposición con el grupo laparoscópico (Fig. 5). En cuanto a los valores promedios, se demostró un aumento significativo de IL-2 en la nefrectomía laparoscópica frente a la nefrectomía abierta $(2,35+0,04$ vs $2,51+0,12, \mathrm{mg} / \mathrm{dl}, \mathrm{p}=0,001)$.

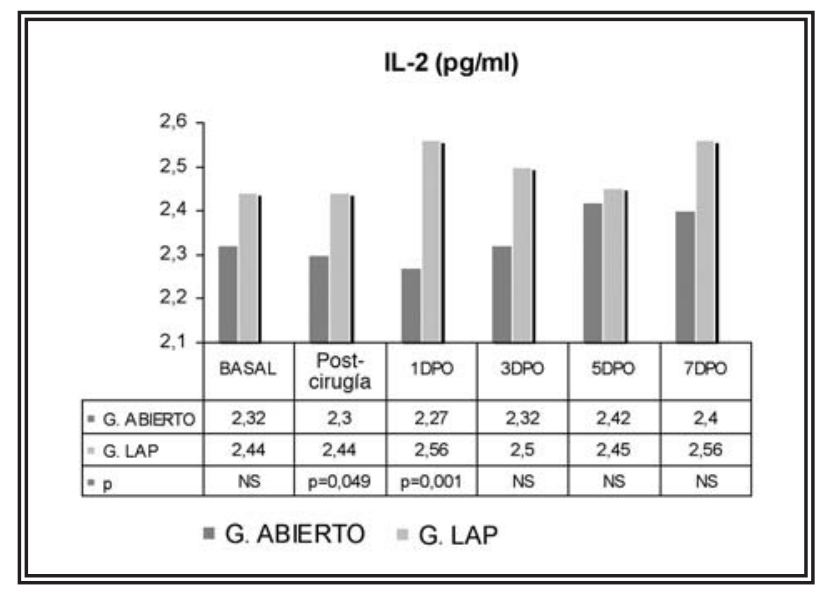

FIGURA 5. Evolución comparativa del valor IL-2 entre los grupos abierto y laparoscópico.
La evolución de los valores la IL-10 se muestran en la Figura 6. Se comportó de la misma forma en la nefrectomía abierta que en la laparoscopia. Aunque los valores basales fueron diferentes para ambos grupos, se igualaron a partir del primer día, manteniendo la misma tendencia levemente ascendente hasta el final. No se detectaron diferencias significativas entre los valores promedio de ambos grupos.

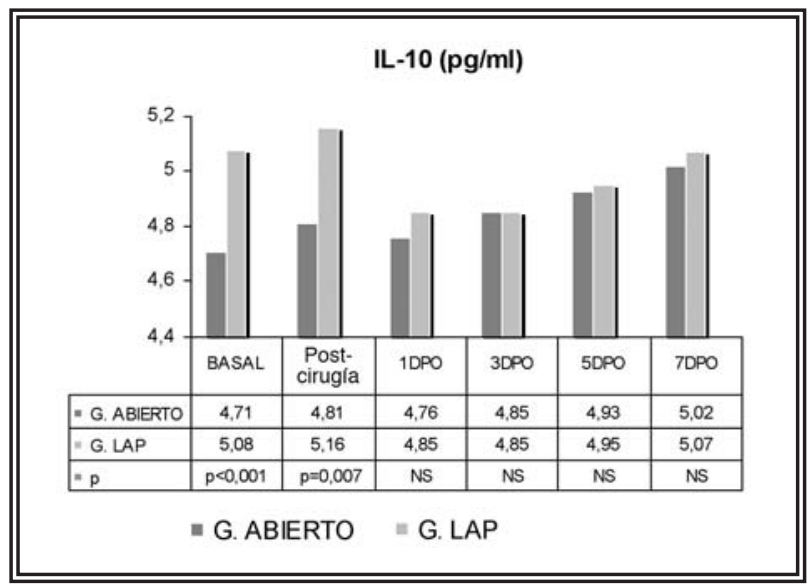

FIGURA 6. Evolución comparativa del valor IL-10 entre los grupos abierto y laparoscópico.

Los valores basales de TNF $\alpha$ en sangre fueron comparables entre ambos grupos, presentando en ambos casos una tendencia levemente ascendente durante el postoperatorio (Fig. 7). Se demostraron valores significativamente superiores en el grupo abierto desde la toma realizada tras la cirugía hasta el $5^{\circ}$ día, igualándose en el $7^{\circ}$ día. Los niveles promedio de TNF $\alpha$ fueron superiores tras la nefrectomía abierta que tras la laparoscópica $(131,14+41,37$ vs $57,19+23,71$ $\mathrm{pg} / \mathrm{ml}, \mathrm{p}<0,001)$.

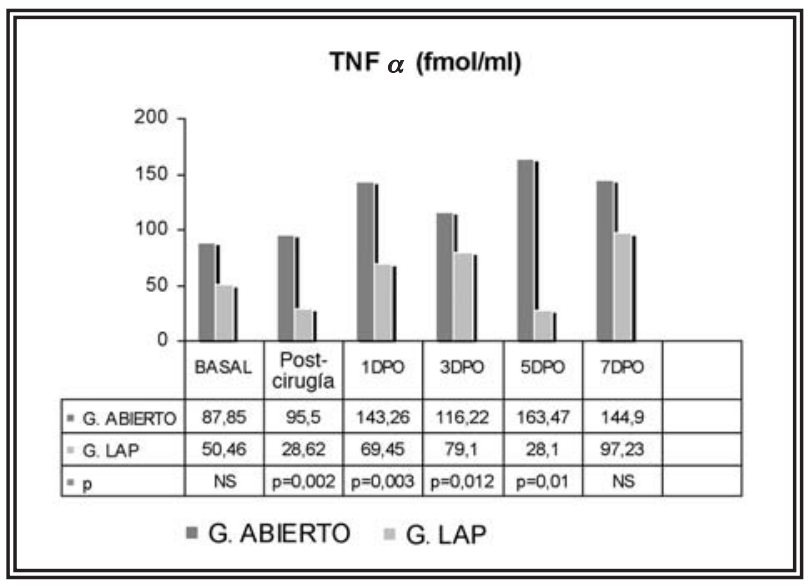

FIGURA 7. Evolución comparativa del valor TNF $\alpha$ entre los grupos abierto y laparoscópico. 
La evolución del valor de la ET-1, durante los primeros siete días postoperatorios en los grupos abierto y laparoscópico se muestran en la Figura 8. La ET-1 presentó unos niveles mas elevados en el grupo abierto que en el laparoscópico desde el postoperatorio inmediato hasta el séptimo día. El valor promedio de la ET-1 del grupo abierto fue mayor que el del grupo laparoscópico $(0,91 \pm 0,49$ vs 0,56 $\pm 0,5 \mathrm{fmol} / \mathrm{ml}, \mathrm{p}=0,001)$.

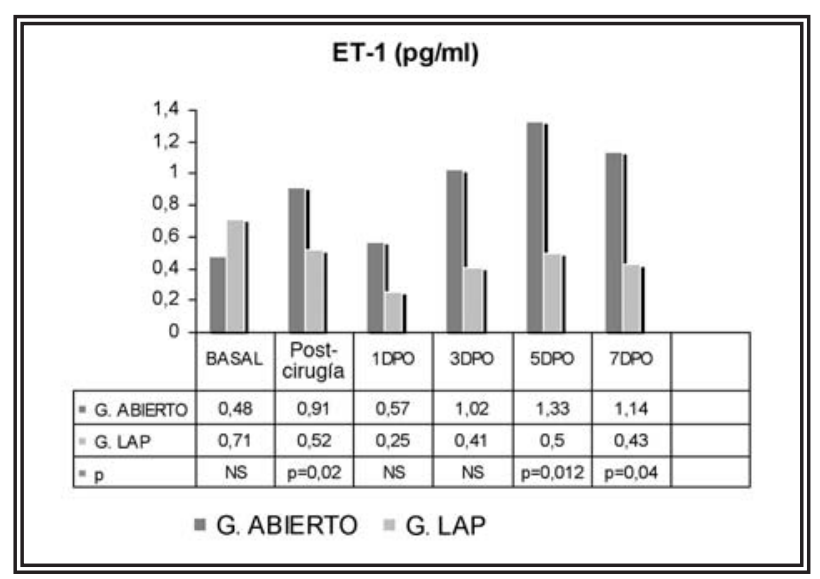

FIGURA 8. Evolución comparativa del valor ET-1 entre los grupos abierto y laparoscópico.

\section{DISCUSIÓN}

La evaluación comparativa del estrés quirúrgico entre la nefrectomía laparoscópica y abierta se ha hecho mediante la medición de marcadores que evalúan distintos elementos del sistema inmune y diferentes fases de la respuesta inflamatoria:

- La PCR como Reactante de fase aguda

- Tres citocinas diferentes:

- La IL-2 como citocina proinflamatoria producida por linfocitos $\mathrm{T}$.

- IL-10 como citocina con efecto supresor de la respuesta inmune.

- El TNF $\alpha$ como citocina proinflamatoria producida por macrófagos.

- La ET-1, hormona vasoconstrictora liberada tras compresión renal.

Fornara et al. ${ }^{20}$ realizaron un modelo porcino que comparaba los niveles de PCR en las 12 horas siguientes a diversos abordajes y técnicas quirúrgicos (nefrectomía bilateral laparoscópica, inserción de trócares e instauración del neumoperitoneo, y laparotomía simple con colocación de separadores). Demostraron que los niveles de PCR se elevan más precozmente y con mayor intensidad en el abordaje abierto que en el laparoscópico.
En el presente estudio, si bien se han producido diferencias significativas en los niveles de PCR entre las nefrectomías abierta y laparoscópica, es destacable que la elevación de la PCR tras la cirugía, en ambos grupos, ha sido mucho menor que en la mayoría de los estudios referidos en humanos, que en algunos casos llega a ser de hasta 15 veces el valor basal ${ }^{21}$. Fornara et al. $^{20}$, en la parte experimental de su estudio, describen elevaciones de PCR mayores que la de nuestro modelo, aunque sin alcanzar niveles tan altos como en humanos (5-10 veces el valor basal). Los resultados de Clary et al. ${ }^{22}$, en un estudio que compara diferentes abordajes quirúrgicos en un modelo de peritonitis inducida en cerdos, se asemejan mucho mas a los de nuestro modelo alcanzando los niveles de PCR valores tan solo entre 2-3 veces el basal.

La explicación podría radicar en la diferencia de las pautas de hidratación y de analgesia perioperatoria entre los estudios de Fornara et al. ${ }^{20}$, el de Clary et al. ${ }^{22}$ y el nuestro. Mientras que en el de Fornara et $a .^{20}$ no se hace referencia a estos factores, tanto en nuestro modelo como en el realizado por Clary, se ha dado especial relevancia a estas circunstancias, jugando ambos un papel indiscutible en la evolución de los niveles de PCR.

Por tanto la PCR en el modelo porcino, aún detectándose diferencias entre los abordajes laparoscópico y abierto, sus modificaciones no alcanzan la misma magnitud que en la clínica humana. En cualquier caso sus modificaciones han de considerarse sometidos a la influencia de factores como la hidratación o la analgesia postoperatoria, que sin duda juegan un papel importante en la cirugía convencional.

La IL-2 es una citocina proinflamatoria producida por los linfocitos T CD4+, cuya activación induce el crecimiento, sobre todo de células $\mathrm{T}$, aunque también de células B y de linfocitos grandes granulo$\operatorname{sos}^{16}$. Asímismo, induce la producción y traducción del RNAm de IL-2, molécula que también ha sido estudiada en algunos trabajos como marcador de agresividad quirúrgica ${ }^{23,24}$.

Landman et al. ${ }^{25}$ realizaron un estudio en humanos con carcinoma renal, sometidos a nefrectomía, bien laparoscópica o abierta, en los que evaluaron, entre otros parámetros, el comportamiento de la IL-2. No se demostraron diferencias entre ambos abordajes. 
$\mathrm{Hu}$ et al. ${ }^{26}$ en un estudio comparativo entre resección rectal laparoscópica y abierta objetivaron un descenso de los niveles de IL-2 en ambos grupos, no detectándose diferencias entre los mismos. Por el contrario, Linares et al. ${ }^{27}$ refieren, en un modelo de autotrasplante renal en cerdos, unos niveles mas altos de IL-2 tras nefrectomía abierta que tras nefrectomía laparoscópica.

Por tanto, el comportamiento de la IL-2 en nuestro modelo sí parece reproducir el que sigue las determinaciones de IL-2 postoperatorias en la clínica humana. Esto es, un descenso inicial de la IL-2 tras cirugía abierta, que no se reproduce en el abordaje laparoscópico que, en nuestro caso, provocó las diferencias entre ambos grupos.

Los niveles de IL-10 fueron semejantes tras las nefrectomías abierta y laparoscópica una vez transcurridas 24 horas de postoperatorio. Si bien es cierto que los niveles basales de IL-10 fueron superiores para el grupo laparoscópico y esas mismas diferencias se mantuvieron hasta después del postoperatorio inmediato, tras las primeras 24 horas desaparecieron las diferencias entre los grupos, presentando los niveles de IL-10 un comportamiento semejante con una relativa estabilidad (Fig. 6).

La IL-10, producida por linfocitos T, B y monocitos activados, ejerce un efecto supresor de la respuesta inmune. La producción endógena de IL-10 es un aspecto importante de la respuesta antinflamatoria que ocurre de forma natural, a través de la inhibición de la síntesis de TNF $\alpha$, IL-1, IL-6, la producción de radicales libres y de óxido nítrico (NO), así como de la expresión de moléculas de adhesión ${ }^{23}$.

Según Fornara et al. ${ }^{20}$, en el ámbito clínico de la nefrectomía, no existen diferencias en los niveles de IL-10, entre los diferentes abordajes quirúrgicos. Tampoco, en el ámbito clínico, se han objetivado diferencias entre los niveles de IL-10 generados por las colecistectomías abiertas y laparoscópicas ${ }^{28}$. No existen trabajos en modelos experimentales porcinos que analicen comparativamente los niveles de IL-10 entre técnicas quirúrgicas laparoscópicas y abiertas.

El presente estudio no evidenció diferencias sustanciales en los niveles de IL-10 entre los grupos abierto y laparoscópico, si bien es cierto que las diferencias existentes en los valores basales y el número limitado de animales incluidos en el estudio impide la obtención de resultados categóricos.
El TNF $\alpha$ es una citocina proinflamatoria producida por macrófagos que actúa activando a otros macrófagos y a los granulocitos, aumentando la adherencia de los leucocitos al endotelio e induciendo la síntesis de proteínas de fase aguda ${ }^{29}$.

Se han realizado numerosos trabajos que evalúan el comportamiento del TNF $\alpha$, tanto en humanos ${ }^{11,30}$ como en animales ${ }^{31}$, como marcador de agresividad quirúrgica. Así, Lausten et al. ${ }^{30}$ y Ordemann et al. ${ }^{11}$ describen niveles mas bajos tras colecistectomía laparoscópica que abierta. Matsumoto et al. ${ }^{31}$ refieren, en un estudio comparativo de tres abordajes (laparoscópico, manoasistido y abierto) de nefrectomía en cerdo, un comportamiento similar del TNF $\alpha$ en todos los grupos hasta las 48 horas posteriores a la cirugía, momento en el que objetivaron unos niveles significativamente inferiores en el grupo laparoscópico.

En nuestro modelo experimental, el comportamiento del TNF $\alpha$, en la nefrectomía abierta, presentó niveles mayores desde el postoperatorio inmediato. Esta elevación de los niveles de TNF $\alpha$ es significativamente superior hasta el $5^{\circ}$ día, momento a partir del cual ambos grupos presentan niveles semejantes.

No existen referencias en la literatura ni a nivel clínico ni experimental que compare los niveles postquirúrgicos de ET-1 entre los abordajes laparoscópico y abierto. En este modelo, se observó que no sólo no se habían producido elevaciones de la ET-1 tras la laparoscopia, sino que los niveles son significativamente inferiores a los del grupo abierto. Estos resultados contradicen los hallazgos de Ambrose y Hamilton que describen un aumento de la ET-1 tras laparoscopia secundario a la compresión de la vena renal por el neumoperitoneo ${ }^{18,19}$. Distintos factores pueden influir en este hallazgo, entre ellos el régimen de administración de fluidos intravenosos elegido, la localización de la recogida de la sangre (vena yugular) o las bajas presiones del neumoperitoneo con las que se trabajó. En cualquier caso, son prácticamente nulas las referencias en la literatura que permitan orientar esta discusión.

No obstante, el papel de la ET-1 en el neumoperitoneo y en la función renal está aún por aclarar, siendo necesarios trabajos comparativos entre ambos abordajes, que además relacionen el gasto cardiaco, la hidratación administrada, la diuresis, la filtración glomerular, el FSR o el flujo de la vena renal y los hallazgos anatomopatológicos. 
En conclusión: la respuesta inmunohumoral inducida por la nefrectomía abierta es superior a la de la nefrectomía laparoscópica en el curso de la donación, en base a la cuantificación de la PCR, el TNF $\alpha$ y la ET-1. La importancia de este hecho en el síndrome isquemia reperfusión postransplante renal o la función inmediata del injerto no está claramente establecida.

\section{REFERENCIAS}

1. Shenkin A, Fraser WD, Series J, Winstanley FP, McCartney AC, Burns HJ, et al: The serum interleukin 6 response to elective surgery. Lymphokine Cytokine Res. 1989;8(2):123-127.

2. Ohzato H, Yoshizaki K, Nishimoto N, Ogata A, Tagoh H, Monden M, Gotoh M, et al. Interleukin-6 as a new indicator of inflammatory status: detection of serum levels of interleukin-6 and C-reactive protein after surgery. Surgery. 1992;111(2):201209.

3. Mehigan BJ, Hartley JE, Drew PJ, Saleh A, Dore PC, Lee PW, et al. Changes in T cell subsets, interleukin- 6 and C-reactive protein after laparoscopic and open colorectal resection for malignancy. Surg Endosc. 2001;15(11):1289-1293.

4. Sakamoto K, Arakawa H, Mita S, Ishiko T, Ikei S, Egami H, et al. Elevation of circulating interleukin 6 after surgery: factors influencing the serum level. Cytokine. 1994;6(2):181-186.

5. Baigrie RJ, Lamont PM, Kwiatkowski D, Dallman MJ, Morris PJ. Systemic cytokine response after major surgery. Br J Surg. 1992;79(8):757-760.

6. Hewitt PM, Ip SM, Kwok SP, Somers SS, Li K, Leung KL, et al. Laparoscopic-assisted vs. open surgery for colorectal cancer: comparative study of immune effects. Dis Colon Rectum. 1998;41(7):901-909.

7. Stage JG, Schulze S, Moller P, Overgaard H, Andersen M, Rebsdorf-Pedersen VB, et al. Prospective randomized study of laparoscopic versus open colonic resection for adenocarcinoma. Br J Surg. 1997;84(3):391-396.

8. Jess P, Schultz K, Bendtzen K, Nielsen OH. Systemic inflammatory responses during laparoscopic and open inguinal hernia repair: a randomised prospective study. Eur J Surg. 2000;166(7):540-544.

9. Leung KL, Lai PB, Ho RL, Meng WC, Yiu RY, Lee JF, et al. Systemic cytokine response after laparoscopic-assisted resection of rectosigmoid carcinoma: a prospective randomized trial. Ann Surg. 2000;231(4):506-511.

10. Tang GJ, Kuo CD, Yen TC, Kuo HS, Chan KH, Yien HW, et al: Perioperative plasma concentrations of tumor necrosis factoralpha and interleukin-6 in infected patients. Crit Care Med. 1996;24(3):423-428.

11. Ordemann J, Jacobi CA, Schwenk W, Stösslein R, Müller JM. Cellular and humoral inflammatory response after laparoscopic and conventional colorectal resections. Surg Endosc. 2001;15(6):600-608.

12. Klava A, Windsor AC, Farmery SM, Woodhouse LF, Reynolds JV, Ramsden CW, et al: Interleukin-10. A role in the development of postoperative immunosuppression. Arch Surg. 1997; 132(4):425-429.

13. Schwenk W, Jacobi C, Mansmann U, Böhm B, Müller JM. Inflammatory response after laparoscopic and conventional colorectal resections results of a prospective randomized trial. Langenbecks Arch Chir. 2000;385(1):2-9.
14. Cruickshank AM, Fraser WD, Burns HJ, Van Damme J, Shenkin A. Response of serum interleukin-6 in patients undergoing elective surgery of varying severity. Clin Sci. 2005;79(2): 161-165.

15. Ohzato H, Yoshizaki K, Nishimoto N, Ogata A, Tagoh H, Monden M, et al: Interleukin-6 as a new indicator of inflammatory status: detection of serum levels of interleukin- 6 and Creactive protein after surgery. Surgery. 2005;111(2):201-209.

16. Faist E, Schinkel C, Zimmer S.. Update on the mechanism of immune suppression of injury and immune modulation. World J Surg. 1996;20(4):454-459.

17. Levin ER. Endothelins. N Engl J Med. 1995;333(6):356-363.

18. Hamilton BD, Chow GK, Stowe NT, et al: Increased intra-abdominal pressure during pneumoperitoneum stimulates endothelin release in a canine model. J Endourol. 1998;12(2):193-197.

19. Ambrose JA, Onders RP, Stowe NT, Simonson MS, Robinson AV, Wilhelm S, et al. Pneumoperitoneum upregulates preproendothelin-1 messenger RNA. Surg Endosc. 2001;15(2):183-188.

20. Fornara P, Doehn C, Seyfarth M, et al. Why is urologycal laparoscopy minimally invasive?. Eur Urol. 2000;37(3):241-250.

21. Sido B, Teklote JR, Hartel M, Friess H, Büchler MW. Inflammatory response after abdominal surgery. Best Pract Res Clin Anaesthesiol. 2004;18(3):439-454.

22. Clary EM, Bruch SM, Lau CL, Ali A, Chekan EG, Garcia-Oria $\mathrm{MJ}$, et al. Effects of Pneumoperitoneum on Hemodynamic and Systemic Immunologic Responses to Peritonitis in Pigs. J Surg Res. 2002;108(1):32-38.

23. Baumann H, Gauldie J. The acute phase response. Immunol Today. 1994;15(2):74-80.

24. Schlag G, Redl H. Mediators of injury and inflammation. World J Surg. 1996;20(4):406-410.

25. Landman J., Olweny E, Sundaram CP, et al: Prospective comparison of the imunological and stress response folowing laparoscopic and open surgery for localized renal cell carcinoma. J Urol 2004; 171: 1456.

26. Hu J, Zhou Z, Chen Z, et al: Comparative evaluation of immune response after laparoscopical and open total mesorectal excisions with anal sphincter preservation in patients with rectal cancer. World J Gastroenterol 2003; 9: 2690.

27. Linares Quevedo AI: Estudio comparativo de la función del transplante renal con donante vivo mediante nefrectomía convencional y laparoscópica. Influencia del síndrome de isquemia repercusión. Modelo experimental. Madrid: 2005

28. Bellon JM, Manzano L, Larrad A, et al: Endocrine and Inmune response to injury after open and laparoscopic cholecystectomy. Int Surg 1998; 83: 24.

29. Pannen HJ , Robotham JL, et al: The acute-phase response. New Horiz 1995; 3: 183.

30. Lausten SB, Ibrahim TM, El-Sefi T, Jensen LS, Gesser B, Larsen CG, et al. Systemic and Cell-Mediated Immune Response after Laparoscopic and Open Cholecystectomy in paitients with chronic liver disease. Dig Surg. 1999;16(6):471-477.

31. Matsumoto ED, Margulis V, Tunc L, Taylor GD, Duchene D, Johnson DB, et al: Cytokine response to surgical stress: comparison of pure laparoscopic, hand-assisted laparoscopic, and open nephrectomy. J endourol. 2005;19(9):1140-1145.

Correspondencia autor: Dr. J. Sáenz Medina

Servicio de Urología. Hospital de Fuenlabrada

Camino del Molino, s/n - 28942 Fuenlabrada (Madrid)

Tel.: 916006000

E-mail autor: javiersaenzmedina@yahoo.es

Información artículo: Original - Trasplante

Trabajo recibido: septiembre 2007

Trabajo aceptado: octubre 2007 